\title{
Dysregulated transcription across diverse cancer types reveals the importance of RNA-binding protein in carcinogenesis
}

\author{
Jing Wang ${ }^{1}$, Qi Liur ${ }^{1,2^{*}}$, Yu Shyr $r^{1,3,4^{*}}$ \\ From The International Conference on Intelligent Biology and Medicine (ICIBM) 2014 \\ San Antonio, TX, USA. 04-06 December 2014
}

\begin{abstract}
Background: It is well known that carcinogenesis is in part dictated by dysregulated transcription events and signal pathways. Large-scale transcriptional profiling studies in each cancer type have reported aberrant gene expression associated with cancer development. However, common and specific patterns altered across cancer types, especially the contribution of transcriptional and post-transcriptional regulators, are rarely explored.
\end{abstract}

Results: Using transcriptional profiles from matched tumor and normal samples in the Cancer Genome Atlas pancancer dataset, we performed a comprehensive analysis on the altered expression across 9 cancer types, focusing on transcriptional and post-transcriptional regulators and cancer-related genes. As we expected, the transcription of cancer-related genes was significantly deregulated in tumor vs. normal across all cancer types. Surprisingly, the expression of RNA-binding proteins (RBPs), master regulators of post-transcriptional gene expression, was also significantly changed across most studied cancer types. Although the expression of RBPs was not as strongly deregulated as cancer-related genes, their direct interaction partners are enriched by cancer-related genes, suggesting the cascade regulation effect of RBPs. Integrating genetic and epigenetic profiles found that deregulated RBPs were frequently caused by genetic rather than epigenetic alterations. Furthermore, tissue-specific genes were under-expressed in tumor vs. normal across all cancer types except prostate cancer.

Conclusions: Dysregulated transcription across cancer types reveals the importance of RBPs in carcinogenesis. The aberrant expression of RBPs is caused by genetic alterations and spreads their effect to cancer-related genes. In addition, disruption of tissue-specific genes contributes to the corresponding cancer pathology.

\section{Background}

Cancer development is characterized by uncontrolled cell proliferation, which is in part due to expression alteration of genes which regulate cell growth and differentiation, such as the improper over-expression of oncogenes, or the under-expression or disabling of tumor suppressor genes [1]. Comparative analysis of expression alterations between tumor and matched normal samples in each individual cancer type has identified many transcriptional and post-transcriptional regulators associated with

\footnotetext{
* Correspondence: qi.liu@vanderbilt.edu; yu.shyr@vanderbilt.edu ${ }^{1}$ Center for Quantitative Sciences, Vanderbilt University School of Medicine, Nashville, TN 37232, USA

Full list of author information is available at the end of the article
}

carcinogenesis [2-13]. For instance, compared to normal mucosa, transcription factor (TF) NRF2 was found overexpressed in head and neck squamous cell carcinoma [2]. Using transcriptional data of 17 adenomas and paired samples of normal mucosa, the transcription-regulating network of colorectal adenomas is characterized by significantly altered expression of over 250 TF genes [13]. Compared to TFs, expression alteration of RNA-binding proteins (RBPs), master regulators at the post-transcriptional level, was less studied but deregulated transcriptions of several RBPs also have been reported to play a critical role in human cancers [9-12]. For example, QKI was frequently down-regulated in lung cancer, and QKI-5 inhibited the proliferation and transformation of 
lung cancer cells [14]. Transcription profiling analysis of RBPs uncovered their aberrant function associated with prostate adenocarcinoma, colon adenocarcinoma, and breast carcinoma as well $[9,12,15]$. Additionally, aberrant expression of microRNAs (miRNAs) and long noncoding RNAs' (lncRNAs') also led to cancer development [16-20]. However, common and specific patterns altered across different cancer types, especially the contribution of transcriptional and post-transcriptional regulators, are rarely known.

Large-scale genomics projects, such as the Cancer Genome Atlas (TCGA), provided various omics data for thousands of tumors with matched normal samples, including genetic, epigenetic, transcriptomics and proteomics data [21], which gave us a great opportunity to perform pan-cancer studies for understanding the common and specific profiles across multiple cancer types. Recently, landscapes of somatic mutation, copy number alterations and oncogenic signatures across major cancer types have been studied [22-24], as well as microRNA-target interaction and functional proteomics data analysis $[25,26]$. However, as far as we know, comparative analysis of expression alterations of transcriptional and post-transcriptional regulators across cancer types has never been explored.

In this study, we characterized the expression perturbation of TFs, RBPs, lncRNAs, cancer related genes (allOnco) and other genes on 522 matched tumor and normal tissue pairs across 9 cancer types. We first analyzed the differential expression between matched tumor and normal for each type of gene sets across all studied cancer types, and compared their amplitude of alterations. Then we integrated genetic and epigenetic data and protein-protein interaction network (PPI) to explain the upstream cause and downstream effect of dysregulated transcription. Finally we compared expression changes of tissue-specific genes with non-specific ones and investigated the consistent pathway changes across different cancer types.

\section{Results and discussion}

\section{Expression alteration of RBPs contributes to cancer development}

Thousands of differentially expressed genes were detected in each individual cancer type. The number of TFs, RBPs, lncRNAs, cancer related genes (allOnco), as well as other genes whose expressions were significantly changed was shown in Table 1. As we expected, allOnco were enriched in the differently expressed genes across all cancer types (Figure 1, Table 1), which was supported by many previous reports [27-31]. Mutations in COSMIC with frameshift, germline and missense mutations were also significantly changed across most cancer types, while those with large deletions, translocations and splicing mutations were not (Figure 1, Table 1) $[32,33]$.

Surprisingly, RBPs were significantly changed in 6 of the 9 cancer types. Marginal significance was observed in PRAD (p-value $=0.01$ ) and HNSC ( $\mathrm{p}$-value $=0.04$ ), while highly statistical significance was detected in COADREAD, LUAD and LUSC ( $\mathrm{p}$-value $=3.82 \mathrm{e}-13$, $1 \mathrm{e}-15$ and $4.04 \mathrm{e}-16$ respectively) (Figure 1). Consistent expression alterations of RBPs across different cancer types suggested that they play an important role in carcinogenesis. Compared to RBPs, TFs only showed marginally significant enrichment in HNSC, possibly due to the fact that the activity changes of TF are at the protein level which cannot be reflected at the transcription level (Figure 1). lncRNAs were significantly depleted across all cancer types (Figure 1), which are possibly biased because only 264 of 9227 lncRNAs were included in the standardized mRNA-Seq data in Firehose (see Materials and Methods). Additionally the expression level of lncRNAs is especially low compared to other regulation factors [15].

To further analysis to which extent expression levels were altered in tumor vs. normal, we compared the amplitude of alterations between TFs, RBPs, lncRNAs and allOnco across cancer types. Similar patterns were observed across all cancer types (Figure 2), where cancerrelated genes changed most and RBPs had the smallest alterations. Since RBPs and cancer-related genes were both significantly changed across most cancer types, we tried to explore the potential relationships between them. As a result, we found the occurrence of differentially expressed genes and cancer-related genes in the interacting proteins of the RBP of interest. Among the top 20 RBPs changed mostly in tumor compared to normal tissue in LUSC, PUF60, DHX36, FIP1L1 and POLR2B were identified that both differentially expressed genes and allOnco were enriched in their directly interacting targets (Figure 3). PUF60, NOP2 and PABPC1 were also identified in LUAD (Additional file 1). It is known that PUF60 involved in apoptosis and transcription regulation and isoform 6 may contribute to tumor progression by enabling increased MYC expression and greater resistance to apoptosis in tumors than in normal cells [34,35]. Moreover, there were 7 allOnco genes (BARD1, ERG, $F H L 2, F U B P 1, H S P D 1, I D 3$ and IGF2BP3) that interacted directly with PUF60 and were also differentially expressed in both LUAD and LUSC (Figure 3 and Additional file 1). BARD1 acts as tumor suppressors, and plays a central role in the control of the cell cycle and death (apoptosis) and regulates cell division [36-38]. Zhang YQ et al. reported that one isoform of BARD1 was specifically upregulated in tumors of non-small cell lung cancer [39]. IGF2BP3, ERG, FUBP1 and FHL2 were also reported being over-expressed/ de-expressed in cancer 
Table 1. Number and significance of differently expressed genes

\begin{tabular}{llllllllll}
\hline CancerType & BRCA & COADREAD & HNSC & KIRC & LIHC & LUAD & LUSC & PRAD & THCA \\
\hline Diff-Expressed & 8556 & 4139 & 2226 & 8210 & 3385 & 6422 & 7981 & 3133 & 5727 \\
TF & 772 & 369 & $233^{*}$ & 667 & 309 & 556 & 704 & 291 & 556 \\
RBP & $383^{* * *}$ & $244^{* * *}$ & $102^{*}$ & 303 & 148 & $354^{* * *}$ & $420^{* * *}$ & $144^{*}$ & 192 \\
IncRNA & 83 & 30 & 14 & 89 & 24 & 46 & 67 & 33 & 54 \\
Other & 7352 & 3522 & 1890 & $7175^{* * *}$ & 2920 & 5506 & 6838 & 2680 & 4943 \\
allOnco & $1020^{*}$ & $445^{*}$ & $313^{* * *}$ & $960^{* * *}$ & $429^{* * *}$ & $752^{* * *}$ & $924^{* * *}$ & $385^{* * *}$ & $661^{* * *}$ \\
COSMIC & $217^{*}$ & 101 & $77^{* * *}$ & $218^{* *}$ & $101^{* *}$ & $177^{* *}$ & $218^{* * *}$ & 67 & $150^{*}$ \\
Fshit & $55^{*}$ & $29^{*}$ & 17 & $58^{* *}$ & $26^{*}$ & $47^{*}$ & $50^{*}$ & 15 & 34 \\
Germ & $44^{*}$ & $28^{* *}$ & 11 & $40^{*}$ & $22^{*}$ & $38^{* *}$ & $39^{*}$ & 14 & $32^{*}$ \\
Missense & $86^{*}$ & $42^{*}$ & $26^{*}$ & $81^{*}$ & $40^{*}$ & $71^{* *}$ & $77^{*}$ & 25 & $59^{*}$ \\
LDel & 18 & 11 & 6 & $20^{*}$ & 9 & 15 & 12 & 1 & 13 \\
Splic & 31 & 16 & 10 & $36^{*}$ & 16 & $32^{*}$ & 30 & 8 & 19 \\
Trans & 127 & 55 & $48^{* *}$ & $131^{*}$ & 53 & 99 & $124^{*}$ & 38 & 88
\end{tabular}

$\mathrm{P}<0.05^{*}, \mathrm{P}<0.001^{* *}, \mathrm{P}<0.0001^{* * *}$

Fshit: frameshift, LDel: large deletions, Trans: translocations, Splic: splicing mutations, and Germ: germline.

[40-45]. These results revealed that expression alteration of RBPs might spread their effect to allOnco, which drives the cancer development.

To explore the upstream regulators that changed the RBPs expression, we first compared the correlations of DNA copy number alterations with expression changes between differentially expressed RBPs and non-differentially expressed RBPs. The correlation was represented as $R^{2}$ to see the extent to which the variation in RBP expression can be explained by DNA copy number alterations at the RBP locus. As aforementioned, RBPs were remarkably enriched in differentially expressed genes in COAD, LUAD and LUSC. Here the results showed that these differentially expressed RBPs had a higher $\mathrm{R}^{2}$ than non-differentially expressed RBPs in all these three cancer types (p-value < 0.05, Wilcoxon rank-sum test; Figure 4A) We also studied the effect of DNA copy number alteration for other 6 studied cancer types and no significance was observed (Additional file 2). We then analyzed the influence of DNA methylation on RBP expression alterations using

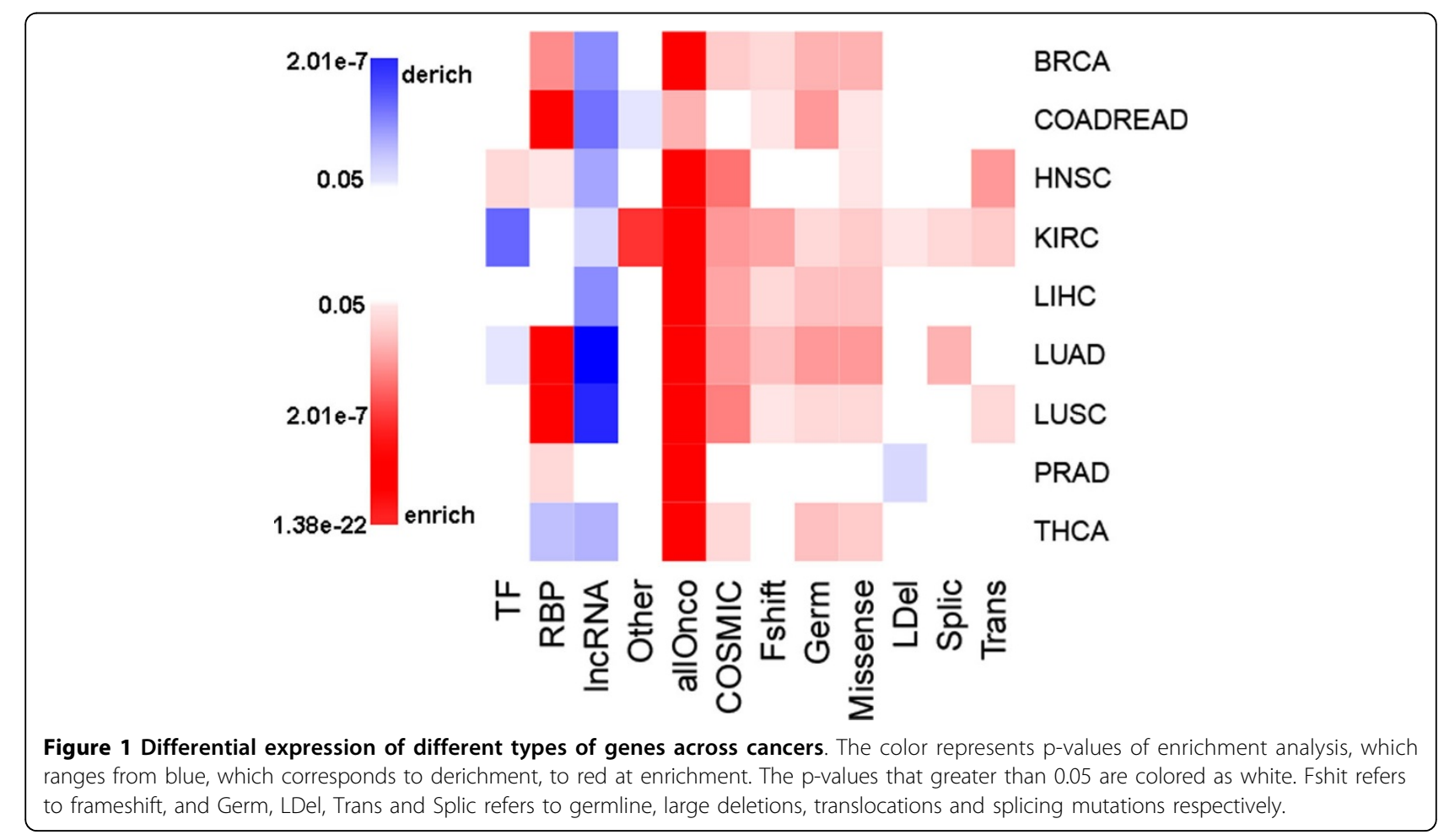



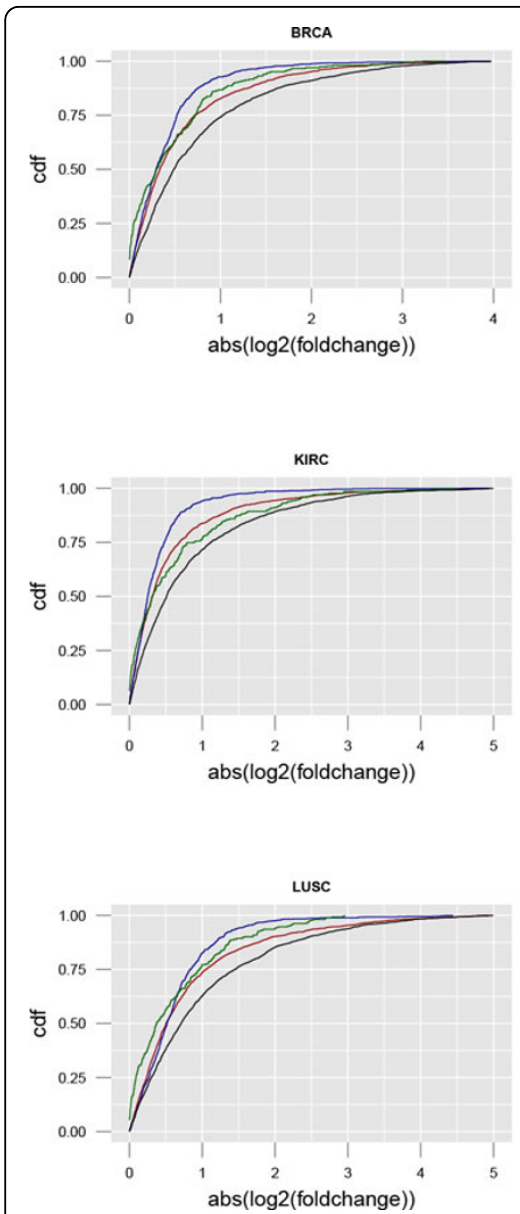
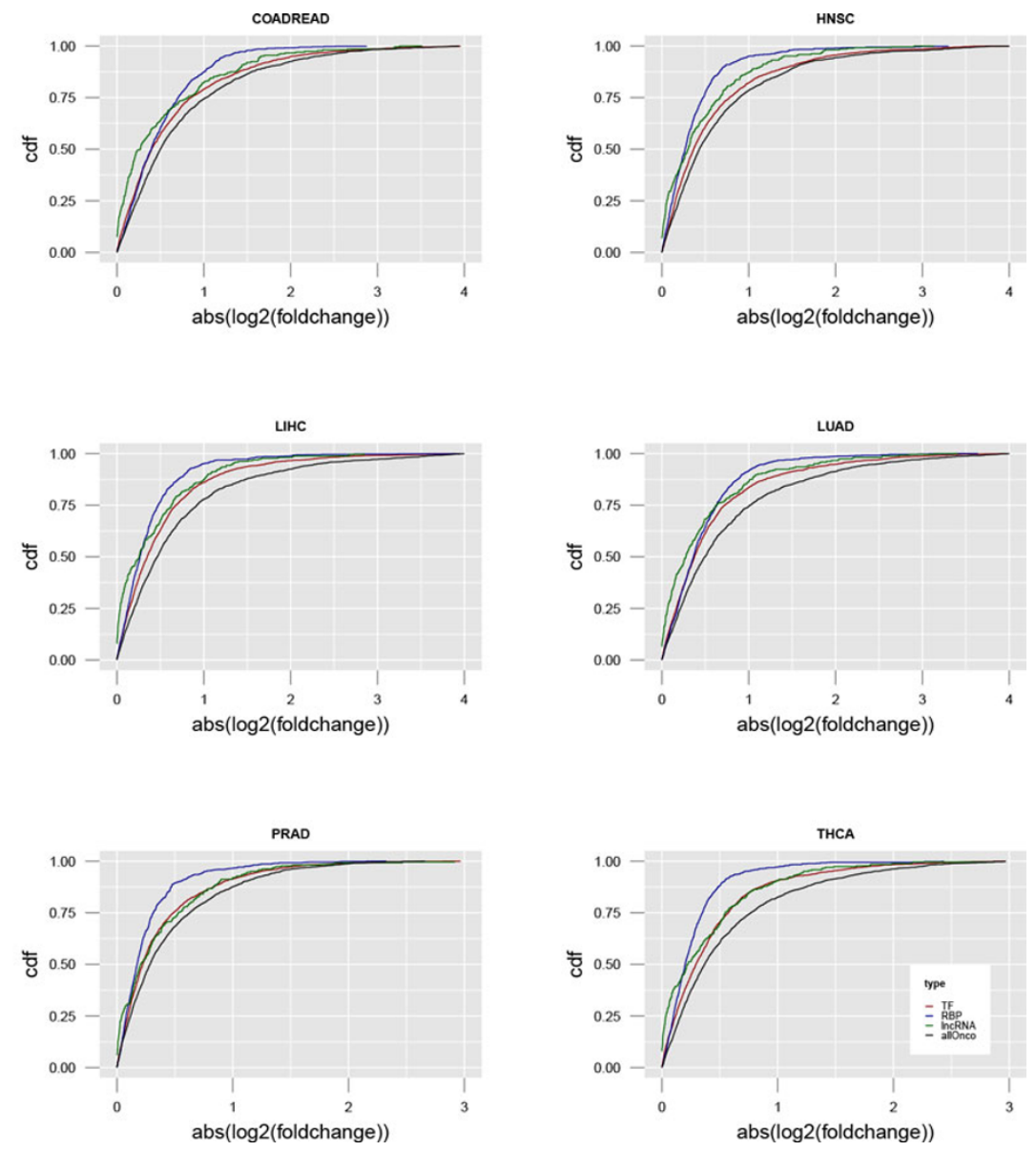

Figure 2 Comparison of expression alterations between RBPs and other kinds of genes. Each of the 9 plots illustrate the cumulative distribution function (cdf) of expression change in tumor vs. normal across BRCA, COADREAD, HNSC, KIRC, LIHC, LUAD, LUSC, PRAD and THCA.

The $x$-axis is the absolute value of log2 transformation of fold change.

similar statistical methods, and results showed that DNA methylation changes were not significantly associated with RBP expression alterations (Figure 4B, Additional file 2). These results suggested that the aberrant expression of RBPs was caused by genetic alterations rather than epigenetic alterations.

\section{Tissue-specific genes lost function in tumor}

It is known that some genes are overexpressed in one or several tissues [46], and these tissue-specific genes are highly correlated with tissue-specific diseases [47]. We sought to better understand the role of tissue-specific genes in pan-cancer. We investigated the profile of 2570 specific genes for 7 tissues from PaGenBase (Methods and Materials) [48], and compared their expression in tumor with that in normal. We observed that tissue-specific genes were more likely to be significantly changed in their corresponding cancer type except prostate-specific genes (Figure 5A). For instance, kidney-specific genes were significantly enriched in differentially expressed genes of
KIRC (p-value $=3.47 \mathrm{e}-5)$ and lung-specific genes showed enrichment in differentially expressed genes for both LUAD and LUSC (p-value $=4.72 \mathrm{e}-7$ and 3.4e-10). However, prostate-specific genes didn't show significance in PRAD, which might be due to the reason that most of the PRAD data were collected from patients in the late stage. Furthermore, most tissue-specific genes were underexpressed in tumor vs. normal across all cancer types except for PRAD (Figure 5B). These results suggested tissue-specific genes generally lost their function in cancer and that defects of tissue-specific genes leads to cancer pathology.

\section{Functional similarity across different cancer types}

Pathways play key roles in genomic studies, and facilitate the understanding of molecular mechanisms behind specific cancers [49]. We estimated the similarity of cancer types not only based on all differentially expressed genes, but also based on the expression alterations of cancerrelated pathways from KEGG [50,51], including pathways 


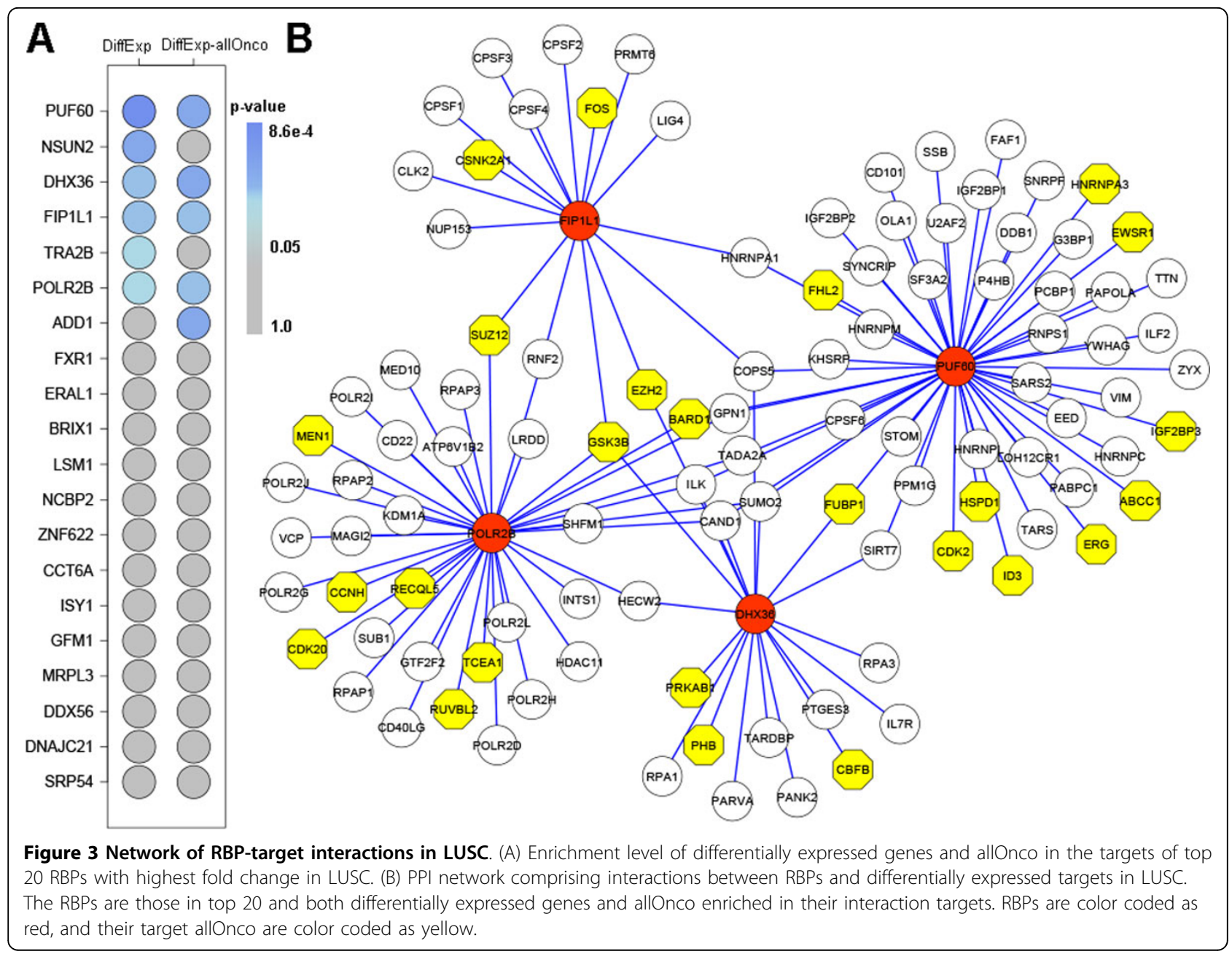

in cancer, cell cycle and the p53 signaling pathway (Figure 6). As we expected, LUAD and LUSC were clustered together in all kinds of clustering, illustrating their close relationship. Surprisingly, BRCA, LIHC, LUAD and LUSC clustered together in the cell cycle pathway, indicating the cell cycle are disrupted similarly in these cancer types [52-54]. Meanwhile, HNSC and COADREAD were more close to each other in the p53 signaling pathway, which can be explained by the similar regulation role of p53 on these two types of cancer $[55,56]$.
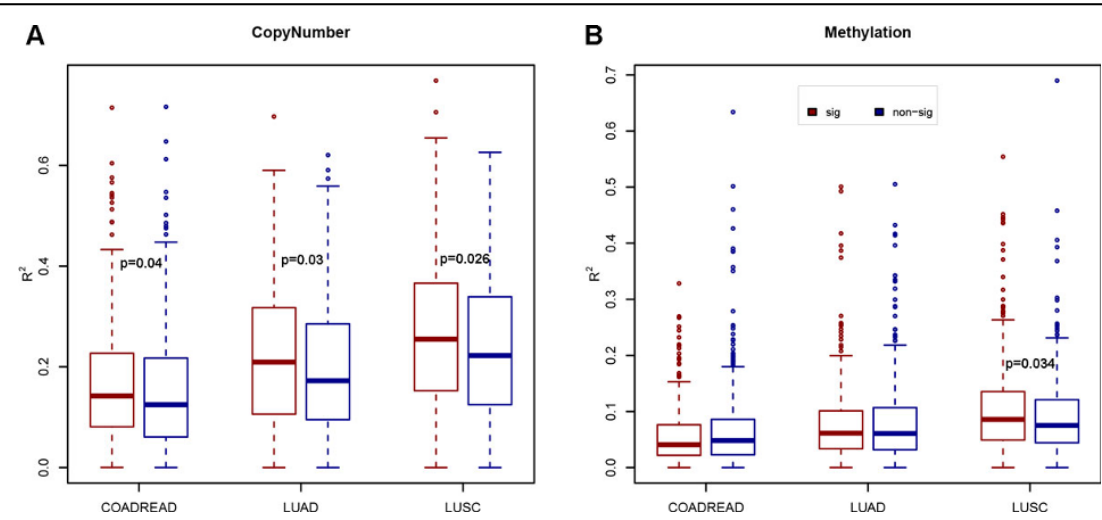

Figure 4 Genetic and epigenetic alterations regulating RBPs. For the differentially expressed and other RBPs in COADREAD, LUAD and LUSC, we estimated the extent to which changes in copy number $(A)$ and methylation (B) could explain the variation in their expression $\left(R^{2}\right)$. 


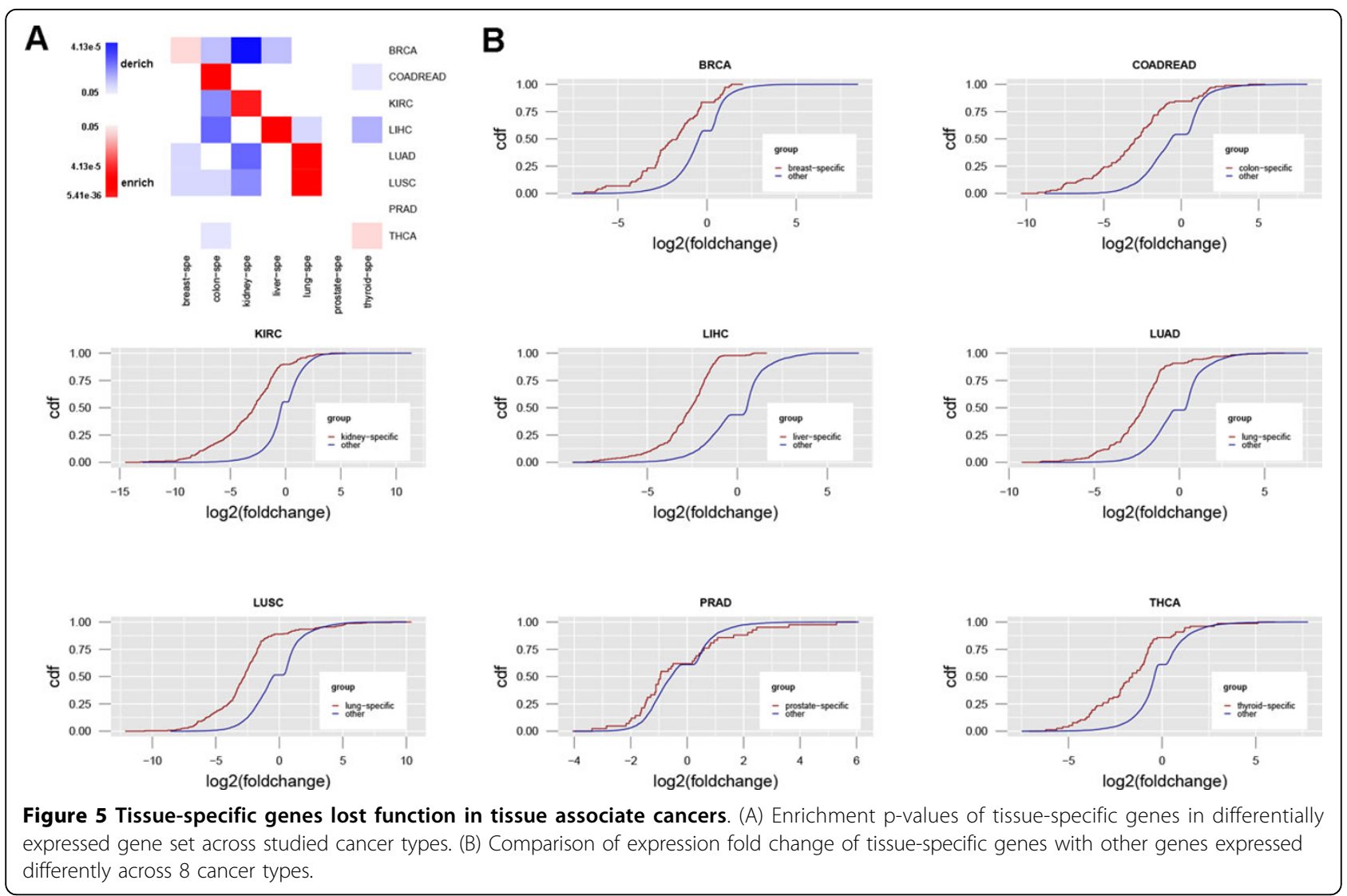

\section{Conclusions}

Dysregulated transcription of RBPs plays an important role in cancer development. The aberrant expression of RBPs is caused by genetic alterations and spreads their effect to cancer-related genes. In addition, disruption of tissue-specific genes contributes to the corresponding cancer pathology.

\section{Methods and materials}

Genetic, epigenetic and transcriptomics data for 9 cancer types

The mRNA-Seq data of 522 matched tumor and adjacent normal samples for 9 cancer types, the copy number alterations, and the DNA methylation data were downloaded from Firehose developed by the Broad GDAC (https://confluence.broadinstitute.org/display/GDAC/ Dashboard-Stddata). The nine cancer types are BRCA (Breast cancer carcinoma), COADREAD (colon/ rectum adenocarcinoma), HNSC (head and neck squamous cell carcinoma), LUAD (lung adenocarcinoma), KIRC (kidney renal clear cell carcinoma), LIHC (liver hepatocellular carcinoma), LUSC (lung squamous cell carcinoma), THCA (thyroid carcinoma) and PRAD (prostate adenocarcinoma). There are 111 paired samples for BRCA, 32 for COADREAD, 41 for HNSC, 72 for KIRC, 57 for
LUAD, 59 pairs for THCA and 50 for each type of LUSC, LIHC and PRAD, respectively.

\section{Different gene sets}

1889 TFs were collected from TRANSFAC [57], and 799 experimentally characterized RBPs were obtained from a recent publication dissecting transcriptional profiles of RNA-binding protein in cancer [15]. Over 9,000 lncRNAs were downloaded from Genecode $[58,59]$, but only 264 of these were included in mRNA-Seq data from the Broad GDAC standardized data packages. A comprehensive list of 2102 cancer related genes (allOnco), which is a non-redundant union of 8 studies [33,60-64], was downloaded from Bushman Lab (http:// www.bushmanlab.org/links/genelists). About 2570 tissue-specific genes were collected from PaGenBase, which defines genes to be tissue-specific if they are dominantly expressed in one tissue. There are 145 breast-specific, 364 colon-specific, 480 kidney-specific, 628 liver-specific, 643 lung-specific, 263 prostate-specific and 227 thyroid-specific genes, respectively [48]. Different types of somatic mutations, including frameshift mutations, germline mutations, missense mutations, large deletions, splicing mutations and translocations were collected from COSMIC [32]. 


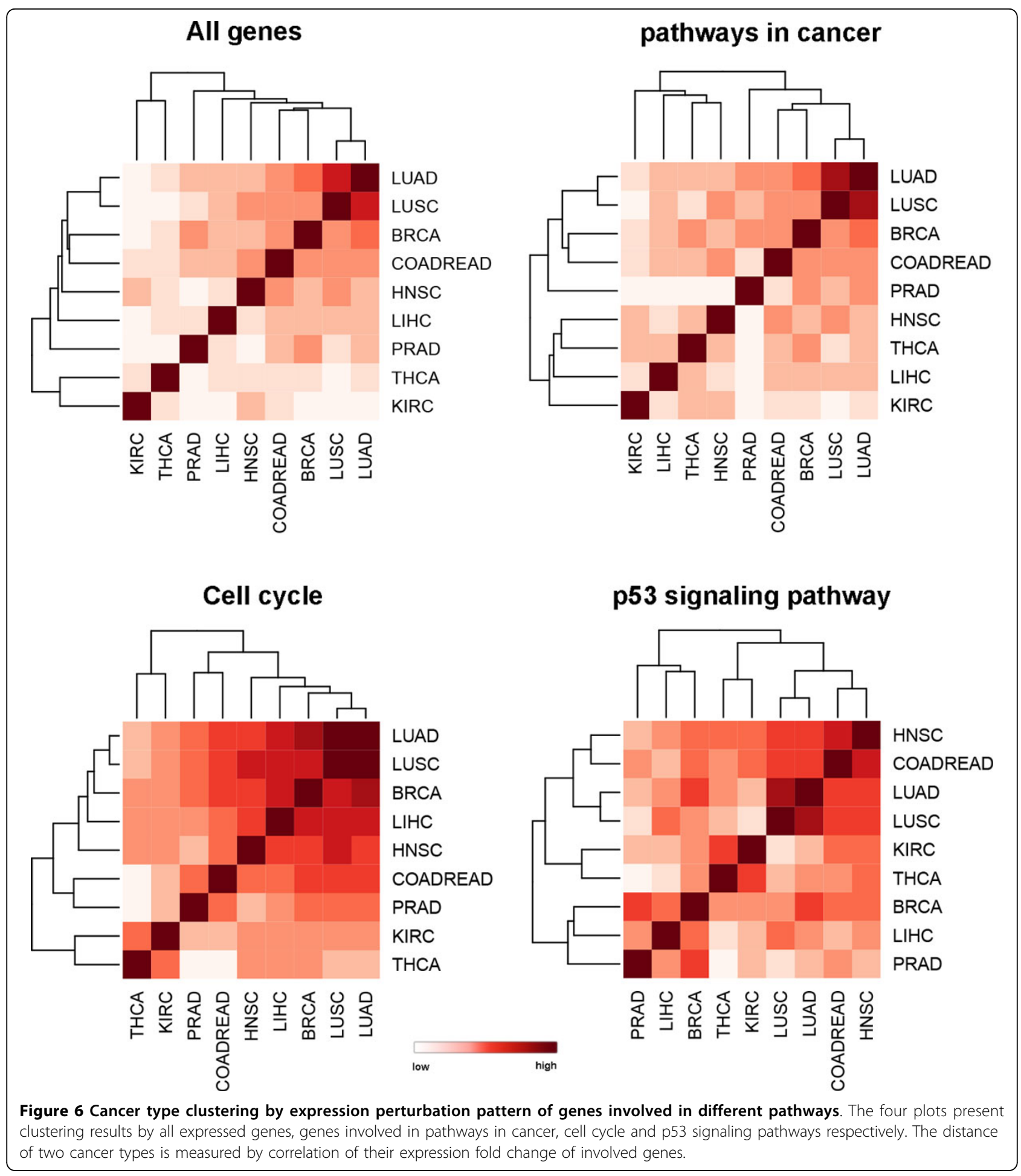

\section{Statistical evaluation of differential expression}

Paired t-test was used to detect differentially expressed genes between matched tumor and normal tissue pairs. Bonferroni method was used to adjust p-values for multiple testing. Hypergeometric test was used to evaluate the enrichment of different types of genes in the set of differentially expressed genes. All statistical tests in this study were implemented in R (version 3.0.3) [65].

Cytoscape was used to visualize Protein-protein interaction data from PINA2 [66]. Only genes interacting with the RBP of interest were shown in Figure 3 and Additional file 1. 
Pairwise Spearman correlations were calculated between the copy number alterations/DNA methylation alterations and gene expression changes for differentially and non-differentially expressed RBPs. The statistical difference of the correlation coefficients were assessed by Wilcoxon Rank Sum test [67].

\section{Clustering by biological pathways}

KEGG pathways are wiring diagrams of molecular interactions, reactions, and relations, and mainly used for biological interpretation of higher-level systemic functions. Different cancers may have consistent changes in some cancer related pathways. To find those pathways similarly altered across different cancers, we performed hierarchal clustering under some specific pathways, including cell cycle, cell proliferation, pathways in cancer and etc. The distance matrix was calculated by Spearman correlation coefficient of expression alteration between different cancer types.

\section{Additional material}

\section{Additional file 1: Network of RBP-target interactions in LUAD.}

(A) Enrichment level of differentially expressed genes and allOnco in the targets of top 20 RBPs with highest fold change in LUAD. (B) PPI network comprising interactions between RBPs and differentially expressed targets in LUAD. The RBPs are those in top 20 and both differentially expressed genes and allOnco enriched in their interaction targets. RBPs are color coded as red, and their target allOnco are color coded as yellow.

Additional file 2: Genetic and epigenetic alterations regulating RBPs. For the differentially expressed and other RBPs in cancer types of BRAD, HNSC, KIRC, LIHC, PRAD and THCA, we estimated the extent to which changes in copy number and methylation could explain the variation in their expression $\left(R^{2}\right)$

\section{Competing interests}

The authors declare that they have no competing interests.

\section{Authors' contributions}

JW carried out the analysis and drafted the manuscript. QL conceived of the study, guided the analysis, and revised the manuscript. YS supervised the research. All authors read and approved the final manuscript.

\section{Acknowledgements}

This work was supported by grants CCSG (P30 CA068485), BETRNet (U01 CA163056), Breast (P50 CA098131), and GI (P50 CA095103).

\section{Declarations}

The publication charges for this article have been funded by the corresponding authors.

This article has been published as part of BMC Genomics Volume 16 Supplement 7, 2015: Selected articles from The International Conference on Intelligent Biology and Medicine (ICIBM) 2014: Genomics. The full contents of the supplement are available online at http://www.biomedcentral.com/ bmcgenomics/supplements/16/S7.

\section{Authors' details}

${ }^{1}$ Center for Quantitative Sciences, Vanderbilt University School of Medicine, Nashville, TN 37232, USA. ${ }^{2}$ Department of Biomedical Informatics, Vanderbilt University School of Medicine, Nashville, TN 37232, USA. ${ }^{3}$ Department of Cancer Biology, Vanderbilt University School of Medicine, Nashville, TN
37232, USA. ${ }^{4}$ Department of Biostatistics, Vanderbilt University School of Medicine, Nashville, TN 37232, USA.

Published: 11 June 2015

\section{References}

1. Croce CM: Oncogenes and cancer. The New England journal of medicine 2008, 358(5):502-511.

2. Stacy DR, Ely K, Massion PP, Yarbrough WG, Hallahan DE, Sekhar KR, Freeman ML: Increased expression of nuclear factor E2 p45-related factor 2 (NRF2) in head and neck squamous cell carcinomas. Head \& neck 2006, 28(9):813-818.

3. Khor TO, Huang MT, Prawan A, Liu Y, Hao X, Yu S, Cheung WK, Chan JY, Reddy BS, Yang CS, et al: Increased susceptibility of Nrf2 knockout mice to colitis-associated colorectal cancer. Cancer prevention research 2008 1(3):187-191

4. Citterio C, Menacho-Marquez M, Garcia-Escudero R, Larive RM, Barreiro O, Sanchez-Madrid F, Paramio JM, Bustelo XR: The rho exchange factors vav2 and vav3 control a lung metastasis-specific transcriptional program in breast cancer cells. Science signaling 2012, 5(244):ra71.

5. Ell B, Kang Y: Transcriptional control of cancer metastasis. Trends in cell biology 2013, 23(12):603-611.

6. Maddox J, Shakya A, South S, Shelton D, Andersen JN, Chidester S, Kang J, Gligorich KM, Jones DA, Spangrude GJ, et al: Transcription factor Oct1 is a somatic and cancer stem cell determinant. PLoS genetics 2012, 8(11): e1003048

7. Wolford CC, McConoughey SJ, Jalgaonkar SP, Leon M, Merchant AS, Dominick JL, Yin X, Chang Y, Zmuda EJ, OToole SA, et al: Transcription factor ATF3 links host adaptive response to breast cancer metastasis. The Journal of clinical investigation 2013, 123(7):2893-2906.

8. Frank DA: Transcription factor STAT3 as a prognostic marker and therapeutic target in cancer. Journal of clinical oncology : official journal of the American Society of Clinical Oncology 2013, 31(36):4560-4561.

9. Lukong KE, Chang KW, Khandjian EW, Richard S: RNA-binding proteins in human genetic disease. Trends in genetics : TIG 2008, 24(8):416-425.

10. Kim MY, Hur J, Jeong S: Emerging roles of RNA and RNA-binding protein network in cancer cells. BMB reports 2009, 42(3):125-130.

11. Castello A, Fischer B, Hentze MW, Preiss T: RNA-binding proteins in Mendelian disease. Trends in genetics: TIG 2013, 29(5):318-327.

12. Wurth L: Versatility of RNA-Binding Proteins in Cancer. Comparative and functional genomics 2012, 2012:178525.

13. Vonlanthen J, Okoniewski MJ, Menigatti M, Cattaneo E, PellegriniOchsner D, Haider R, Jiricny J, Staiano T, Buffoli F, Marra G: A comprehensive look at transcription factor gene expression changes in colorectal adenomas. BMC cancer 2014, 14:46.

14. Zong FY, Fu X, Wei WJ, Luo YG, Heiner M, Cao LJ, Fang Z, Fang R, Lu D, $\mathrm{Ji}$, et al: The RNA-binding protein QKI suppresses cancer-associated aberrant splicing. PLOS genetics 2014, 10(4):e1004289.

15. Kechavarzi B, Janga SC: Dissecting the expression landscape of RNAbinding proteins in human cancers. Genome biology 2014, 15(1):R14

16. Sassen S, Miska EA, Caldas C: MicroRNA: implications for cancer. Virchows Archiv : an international journal of pathology 2008, 452(1):1-10.

17. Vincent K, Pichler M, Lee GW, Ling H: MicroRNAs, Genomic Instability and Cancer. International journal of molecular sciences 2014, 15(8):14475-14491.

18. Prensner JR, Chinnaiyan AM: The emergence of IncRNAs in cancer biology. Cancer discovery 2011, 1(5):391-407.

19. Zhang $H$, Chen Z, Wang $X$, Huang Z, He Z, Chen Y: Long non-coding RNA: a new player in cancer. Journal of hematology \& oncology 2013, 6:37.

20. Cheetham SW, Gruhl F, Mattick JS, Dinger ME: Long noncoding RNAs and the genetics of cancer. British journal of cancer 2013, 108(12):2419-2425.

21. Cancer Genome Atlas Research N, Weinstein JN, Collisson EA, Mills GB, Shaw KR, Ozenberger BA, Ellrott K, Shmulevich I, Sander C, Stuart JM: The Cancer Genome Atlas Pan-Cancer analysis project. Nature genetics 2013, 45(10):1113-1120.

22. Zack TI, Schumacher SE, Carter SL, Cherniack AD, Saksena G, Tabak B, Lawrence MS, Zhang CZ, Wala J, Mermel $\mathrm{CH}$, et al: Pan-cancer patterns of somatic copy number alteration. Nature genetics 2013, 45(10):1134-1140.

23. Kandoth C, McLellan MD, Vandin F, Ye K, Niu B, Lu C, Xie M, Zhang Q, McMichael JF, Wyczalkowski MA, et al: Mutational landscape and significance across 12 major cancer types. Nature 2013, 502(7471):333-339. 
24. Ciriello G, Miller ML, Aksoy BA, Senbabaoglu Y, Schultz N, Sander C: Emerging landscape of oncogenic signatures across human cancers. Nature genetics 2013, 45(10):1127-1133.

25. Jacobsen A, Silber J, Harinath G, Huse JT, Schultz N, Sander C: Analysis of microRNA-target interactions across diverse cancer types. Nature structural \& molecular biology 2013, 20(11):1325-1332.

26. Li J, Lu Y, Akbani R, Ju Z, Roebuck PL, Liu W, Yang JY, Broom BM, Verhaak RG, Kane DW, et al: TCPA: a resource for cancer functional proteomics data. Nature methods 2013, 10(11):1046-1047.

27. Zhang L, Zhou W, Velculescu VE, Kern SE, Hruban RH, Hamilton SR, Vogelstein B, Kinzler KW: Gene expression profiles in normal and cancer cells. Science 1997, 276(5316):1268-1272.

28. Li ML, Zhang JC, Li SG, Wu WG, Rao LH, Dong P, Gu J, Lu JH, Zhang L, Ding QC, et al: Characteristic gene expression profiles in the progression from normal gastric epithelial cells to moderate gastric epithelial dysplasia and to gastric cancer. Chinese medical journal 2012, 125(10):1777-1783.

29. Hu YC, Lam KY, Law S, Wong J, Srivastava G: Profiling of differentially expressed cancer-related genes in esophageal squamous cell carcinoma (ESCC) using human cancer CDNA arrays: overexpression of oncogene MET correlates with tumor differentiation in ESCC. Clinical cancer research : an official journal of the American Association for Cancer Research 2001, 7(11):3519-3525

30. Hu J, Locasale JW, Bielas JH, O'Sullivan J, Sheahan K, Cantley LC, Vander Heiden MG, Vitkup D: Heterogeneity of tumor-induced gene expression changes in the human metabolic network. Nature biotechnology 2013, 31(6):522-529.

31. Lowe AW, Olsen M, Hao Y, Lee SP, Taek Lee K, Chen X, van de Rijn M, Brown PO: Gene expression patterns in pancreatic tumors, cells and tissues. PloS one 2007, 2(3):e323.

32. Santarius T, Shipley J, Brewer D, Stratton MR, Cooper CS: A census of amplified and overexpressed human cancer genes. Nature reviews Cancer 2010, 10(1):59-64.

33. Futreal PA, Coin L, Marshall M, Down T, Hubbard T, Wooster R, Rahman N, Stratton MR: A census of human cancer genes. Nature reviews Cancer 2004, 4(3):177-183.

34. Liu J, Kouzine F, Nie Z, Chung HJ, Elisha-Feil Z, Weber A, Zhao K, Levens D: The FUSE/FBP/FIR/TFIIH system is a molecular machine programming a pulse of c-myc expression. The EMBO journal 2006, 25(10):2119-2130.

35. Page-McCaw PS, Amonlirdviman K, Sharp PA: PUF60: a novel U2AF65related splicing activity. Rna 1999, 5(12):1548-1560.

36. Edwards RA, Lee MS, Tsutakawa SE, Williams RS, Nazeer I, Kleiman FE, Tainer JA, Glover JN: The BARD1 C-terminal domain structure and interactions with polyadenylation factor CstF-50. Biochemistry 2008, 47(44):11446-11456.

37. Fabbro M, Savage K, Hobson K, Deans AJ, Powell SN, McArthur GA, Khanna KK: BRCA1-BARD1 complexes are required for p53Ser-15 phosphorylation and a $\mathrm{G} 1 / \mathrm{S}$ arrest following ionizing radiation-induced DNA damage. The Journal of biological chemistry 2004, 279(30):31251-31258.

38. Ryser S, Dizin E, Jefford CE, Delaval B, Gagos S, Christodoulidou A, Krause $\mathrm{KH}$, Birnbaum D, Irminger-Finger I: Distinct roles of BARD1 isoforms in mitosis: full-length BARD1 mediates Aurora $B$ degradation, cancerassociated BARD1beta scaffolds Aurora B and BRCA2. Cancer research 2009, 69(3):1125-1134.

39. Zhang YQ, Bianco A, Malkinson AM, Leoni VP, Frau G, De Rosa N, Andre PA, Versace $R$, Boulvain M, Laurent GJ, et al: BARD1: an independent predictor of survival in non-small cell lung cancer. International journal of cancer Journal international du cancer 2012, 131(1):83-94.

40. Yamamoto H, Arakaki K, Morimatsu K, Zaitsu Y, Fujita A, Kohashi K, Hirahashi M, Motoshita J, Oshiro Y, Oda Y: Insulin-like growth factor II messenger RNA-binding protein 3 expression in gastrointestinal mesenchymal tumors. Human pathology 2014, 45(3):481-487.

41. Lin L, Zhang J, Wang Y, Zheng L, Lin Z, Cai Y: Expression of insulin-like growth factor 2 mRNA-binding protein 3 expression and analysis of prognosis in the patients with lung squamous cell carcinoma. $X_{i}$ bao yu fen zi mian yi xue za zhi = Chinese journal of cellular and molecular immunology 2013, 29(7):694-697.

42. Lin CY, Chen ST, Jeng YM, Yeh CC, Chou HY, Deng YT, Chang CC, Kuo MY: Insulin-like growth factor II mRNA-binding protein 3 expression promotes tumor formation and invasion and predicts poor prognosis in oral squamous cell carcinoma. Journal of oral pathology \& medicine : official publication of the International Association of Oral Pathologists and the American Academy of Oral Pathology 2011, 40(9):699-705.

43. Flajollet S, Tian TV, Flourens A, Tomavo N, Villers A, Bonnelye E, Aubert S, Leroy $X$, Duterque-Coquillaud M: Abnormal expression of the ERG transcription factor in prostate cancer cells activates osteopontin. Molecular cancer research : MCR 2011, 16(7):914-924.

44. Baumgarten P, Harter PN, Tonjes M, Capper D, Blank AE, Sahm F, von Deimling A, Kolluru V, Schwamb B, Rabenhorst U, et al: Loss of FUBP1 expression in gliomas predicts FUBP1 mutation and is associated with oligodendroglial differentiation, IDH1 mutation and 1p/19q loss of heterozygosity. Neuropathology and applied neurobiology 2014, 40(2):205-216.

45. Martin BT, Kleiber K, Wixler V, Raab M, Zimmer B, Kaufmann M, Strebhardt K. FHL2 regulates cell cycle-dependent and doxorubicin-induced p21Cip1/ Waf1 expression in breast cancer cells. Cell cycle 2007, 6(14):1779-1788.

46. Xiao SJ, Zhang C, Zou Q, Ji ZL: TiSGeD: a database for tissue-specific genes. Bioinformatics 2010, 26(9):1273-1275.

47. Lage K, Hansen NT, Karlberg EO, Eklund AC, Roque FS, Donahoe PK, Szallasi Z, Jensen TS, Brunak S: A large-scale analysis of tissue-specific pathology and gene expression of human disease genes and complexes. Proceedings of the National Academy of Sciences of the United States of America 2008, 105(52):20870-20875.

48. Pan JB, Hu SC, Shi D, Cai MC, Li YB, Zou Q, Ji ZL: PaGenBase: a pattern gene database for the global and dynamic understanding of gene function. PloS one 2013, 8(12):e80747.

49. Kanehisa M: Post-genome informatics Oxford; New York: Oxford University Press; 2000.

50. Kanehisa M, Goto S: KEGG: kyoto encyclopedia of genes and genomes. Nucleic acids research 2000, 28(1):27-30.

51. Kanehisa M, Goto S, Sato Y, Kawashima M, Furumichi M, Tanabe M: Data, information, knowledge and principle: back to metabolism in KEGG. Nucleic acids research 2014, 42(Database):D199-205.

52. Bisteau X, Caldez MJ, Kaldis P: The Complex Relationship between Liver Cancer and the Cell Cycle: A Story of Multiple Regulations. Cancers 2014, 6(1):79-111.

53. Vincenzi B, Schiavon G, Silletta M, Santini D, Perrone G, Di Marino M, Angeletti S, Baldi A, Tonini G: Cell cycle alterations and lung cancer. Histology and histopathology 2006, 21(4):423-435.

54. Caldon CE, Daly RJ, Sutherland RL, Musgrove EA: Cell cycle control in breast cancer cells. Journal of cellular biochemistry 2006, 97(2):261-274.

55. Ma Q, Wang X, Li Z, Li B, Ma F, Peng L, Zhang Y, Xu A, Jiang B: microRNA16 represses colorectal cancer cell growth in vitro by regulating the p53/survivin signaling pathway. Oncology reports 2013, 29(4):1652-1658.

56. Rothenberg SM, Ellisen LW: The molecular pathogenesis of head and neck squamous cell carcinoma. The Journal of clinical investigation 2012, 122(6):1951-1957.

57. Matys V, Fricke E, Geffers R, Gossling E, Haubrock M, Hehl R, Hornischer K, Karas D, Kel AE, Kel-Margoulis OV, et al: TRANSFAC: transcriptional regulation, from patterns to profiles. Nucleic acids research 2003, 31(1):374-378.

58. Derrien $T$, Johnson R, Bussotti $G$, Tanzer A, Djebali S, Tilgner H, Guernec $G$, Martin D, Merkel A, Knowles DG, et al: The GENCODE v7 catalog of human long noncoding RNAs: analysis of their gene structure, evolution, and expression. Genome research 2012, 22(9):1775-1789.

59. Harrow J, Frankish A, Gonzalez JM, Tapanari E, Diekhans M, Kokocinski F, Aken BL, Barrell D, Zadissa A, Searle S, et al: GENCODE: the reference human genome annotation for The ENCODE Project. Genome research 2012, 22(9):1760-1774.

60. Huret JL, Ahmad M, Arsaban M, Bernheim A, Cigna J, Desangles F, Guignard JC, Jacquemot-Perbal MC, Labarussias M, Leberre V, et al: Atlas of genetics and cytogenetics in oncology and haematology in 2013. Nucleic acids research 2013, 41(Database):D920-924.

61. Sjoblom T, Jones S, Wood LD, Parsons DW, Lin J, Barber TD, Mandelker D, Leary RJ, Ptak J, Silliman N, et al: The consensus coding sequences of human breast and colorectal cancers. Science 2006, 314(5797):268-274.

62. Akagi K, Suzuki T, Stephens RM, Jenkins NA, Copeland NG: RTCGD: retroviral tagged cancer gene database. Nucleic acids research 2004, 32(Database):D523-527.

63. Coffin JM: Retroviruses. Cold Spring Harbor, NY: Cold Spring Harbor Laboratory Press; 2002, 1 CD-ROM. 
64. Vogelstein B, Papadopoulos N, Velculescu VE, Zhou S, Diaz LA, Kinzler KW: Cancer genome landscapes. Science 2013, 339(6127):1546-1558.

65. Team RC: R: A Language and Environment for Statistical Computing. 2014

66. Saito R, Smoot ME, Ono K, Ruscheinski J, Wang PL, Lotia S, Pico AR, Bader GD, Ideker T: A travel guide to Cytoscape plugins. Nature methods 2012, 16(11):1069-1076.

67. Hollander M, Wolfe DA: Nonparametric statistical methods New York: Wiley; 1973.

doi:10.1186/1471-2164-16-S7-S5

Cite this article as: Wang et al:. Dysregulated transcription across

diverse cancer types reveals the importance of RNA-binding protein in carcinogenesis. BMC Genomics 2015 16(Suppl 7):S5.

Submit your next manuscript to BioMed Central and take full advantage of:

- Convenient online submission

- Thorough peer review

- No space constraints or color figure charges

- Immediate publication on acceptance

- Inclusion in PubMed, CAS, Scopus and Google Scholar

- Research which is freely available for redistribution

Submit your manuscript at www.biomedcentral.com/submit 